\title{
Erratum to: Incentives for creativity
}

\author{
Sanjiv Erat ${ }^{1} \cdot$ Uri Gneezy $^{1,2}$
}

\section{Erratum to: Exp Econ (2016) 19:269-280 \\ DOI 10.1007/s10683-015-9440-5}

In the part of the instructions to participants that explains the rebus-puzzle design task in our paper "Incentives for Creativity" (Erat and Gneezy 2016), there are several shared phrases from Kachelmeier et al. (2008). We failed to cite them, and wish to correct this here. In their paper, Kachelmeier et al. (2008) examine how worker productivity differs when compensation is based on quantity, creativity, or the product of both measures. They find that combining quantity and creativity measures in a creativity-weighted pay scheme results in creativity weighted productivity scores that are significantly lower than those generated by participants with quantity incentives alone. See also Kachelmeier and Williamson (2010) for a follow-up study on self-selection, which shows that participants choosing a creativity-based incentive scheme exhibit more creativity initially, but are not any more creative overall.

The online version of the original article can be found under doi:10.1007/s10683-015-9440-5.

Sanjiv Erat

serat@ucsd.edu

Uri Gneezy

ugneezy@ucsd.edu

1 Rady School of Management, University of California, San Diego, USA

2 CREED, University of Amsterdam, Amsterdam, The Netherlands 


\section{References}

Erat, S., \& Gneezy, U. (2016). Incentives for creativity. Experimental Economics, 19, 269-280.

Kachelmeier, S. J., Reichert, B. E., \& Williamson, M. G. (2008). Measuring and motivating quantity creativity, or both. Journal of Accounting Research, 46(2), 341-373.

Kachelmeier, S. J., \& Williamson, M. G. (2010). Attracting creativity: The initial and aggregate effects of contract section on creativity-weighted productivity. The Accounting Review, 85(5), 1669-1691. 